\title{
Avaliação dos erros em técnicas radiográficas intraorais causados por acadêmicos do curso de Odontologia
}

\section{Evaluation of errors in intraoral radiographic techniques caused by academics from Dentistry course}

\author{
Pedro Henrique Cossu Vallejo ${ }^{1}$, Eduardo Hideki Otani ${ }^{1}$, João Vitor Fantinati Marques Pereira ${ }^{1}$, \\ Hélio Massaiochi Tanimoto 2,3
}

\begin{abstract}
${ }^{1}$ Aluno do Curso de Odontologia do Centro Universitário da Fundação Educacional de Barretos. ${ }^{2}$ Preceptor do departamento de Odontologia do Hospital de Câncer de Barretos-Fundação Pio XII, Barretos - SP. ${ }^{3}$ Professor Doutor do Curso de Odontologia do Centro Universitário da Fundação Educacional de Barretos.
\end{abstract}

\section{Resumo}

A radiografia é um exame complementar muito utilizado para auxiliar o exame clínico. A qualidade da radiografia é de primordial importância para a interpretação correta da imagem, fornecendo informações para realizar o correto diagnóstico e tratamento. O objetivo deste trabalho é quantificar e analisar os erros mais frequentes nas radiografias periapicais, oclusais e interproximais realizadas por acadêmicos do $2^{\circ}$ ano do curso de Odontologia do Centro Universitário da Fundação Educacional de Barretos (UNIFEB), na disciplina de Radiologia, durante o período de um ano. Os erros que foram analisados são: enquadramento do filme, enquadramento do cilindro de raio $\mathrm{X}$, angulagem, definição de imagem, exposição na face da lâmina de chumbo, posição do picote, processamento da película radiográfica. As radiografias que apresentavam pelo menos um desses erros foram consideradas insatisfatórias. Os três erros mais frequentes nas radiografias periapicais foram: alongamento $(13,40 \%)$, erro de radiografias riscadas, com impressão digital ou coladas $(13,15 \%)$ e erro de posicionamento incorreto do filme $(12,23 \%)$. Nas radiografias oclusais, os três erros mais frequentes foram: radiografia mal lavada $(13,83 \%)$, erro de área de incidência $(13,61 \%)$ e erro de radiografias riscadas, com impressão digital ou coladas (12,50\%). Já nas radiografias interproximais, os três erros mais frequentes foram: angulagem horizontal $(17,97 \%)$, erro de posicionamento incorreto do filme $(17,43 \%)$ e erro de radiografias riscadas, com impressão digital ou coladas $(13,45 \%)$. Logo, o erro que mais ocorreu nas periapicais foi o de alongamento, nas oclusais foi o de radiografia mal lavada e nas interproximais foi o de angulagem horizontal.

Palavras-chave: radiografia odontológica; controle de qualidade; acadêmicos de odontologia; diagnóstico.

\begin{abstract}
Radiography is a complementary exam widely used to assist clinical examination. The quality of the radiography is of paramount importance for the correct interpretation of the image, providing information to carry out the correct diagnosis and treatment. The objective of this work is to quantify and analyze the most frequent errors in periapical, occlusal, and interproximal radiographs taken by second-year students of the Dentistry course at the University Center of Educational Foundation of Barretos (UNIFEB), in the
\end{abstract}

\footnotetext{
*Autor para correspondência: Pedro Henrique Cossu Vallejo E-mail: drpedrohcv@gmail.com; Tel. (17) 997745930
}

Recebido para publicação: 02/Nov./2020

Aceito para Publicação: 04/Mar./2021

https://doi.org/10.4322/1980-0029.102021 
Radiology discipline, during one year. The analyzed errors were framing the film, framing the X-ray cylinder, angulation, image definition, exposure on the face of the lead blade, perforation position, and radiographic film processing. Radiographs showing at least one of these errors were considered unsatisfactory. The three most frequent errors in periapical radiographs were stretching (13.40\%), error of scratched radiographs with fingerprints or glued (13.15\%), and incorrect positioning of the film (12.23\%). In occlusal radiographs, the three most frequent errors were poorly washed radiography (13.83\%), incidence area error $(13.61 \%)$, and error in scratched radiographs with fingerprints or glued (12.50\%). In the interproximal radiographs, the three most frequent errors were horizontal angulation (17.97\%), incorrect positioning of the film $(17.43 \%)$, and error of scratched radiographs with fingerprints or glued (13.45\%). Therefore, the error that most occurred in the periapical images was stretching, in the occlusal, was the poorly washed radiography, and in the interproximal was the horizontal angle.

Keywords: dental radiography; quality control; dental students; diagnosis.

\section{Introdução}

A descoberta dos raios X ocorreu em 1895, pelo Professor de matemática e física, Wilhelm Conrad Röntgen e a primeira radiografia dentária foi realizada pelo Dr. Otto Walkhoff em sua própria boca, utilizando uma placa fotográfica de vidro com um papel preto em seu redor, com tempo de 25 minutos de exposição. A partir disso, a medicina e a odontologia obtiveram um grande avanço, pois a radiografia permite complementar e sanar dúvidas de diagnósticos, possibilitando o profissional produzir um planejamento mais seguro do tratamento, podendo utilizá-la na proservação e documentação de um modo geral. Logo, essa tecnologia disponibiliza aos diversos profissionais especialistas da área odontológica, informações úteis para a sua atuação clínica, desde que empregada de modo adequado (Eid \& Magalhães Filho, 2017; Mendonça et al., 2013; Kreich et al., 2002; Brandt et al., 1997).

O exame radiográfico é um dos diversos exames complementares e tem essencial importância para o diagnóstico, planejamento, análise clínica, realização e proservação do tratamento. Dessa forma, para que a radiografia transmita as informações de forma fiel e cumpra sua importância na elaboração do diagnóstico, deve-se realizar a técnica, o processamento e armazenamento de maneira correta. Portanto, de acordo com a Organização Mundial da Saúde (OMS), se a qualidade da imagem radiográfica for baixa, a determinação do diagnóstico será prejudicada (Eid \& Magalhães Filho, 2017; Silva et al., 2016; Mendonça et al., 2013; Carvalho et al., 2009; Whaites, 2003; Kreich et al., 2002; Teunen, 1998).

O Ministério da Saúde publicou a Portaria $\mathrm{n}^{\circ}$ 453, em junho de 1998, regulamentando a utilização dos raios X para o diagnóstico em odontologia e medicina. Em consequência, foi implementado o Programa de Controle de Qualidade em radiologia odontológica, que visa uma fiscalização rigorosa e controlada de equipamentos e procedimentos, com intuito de mostrar falhas e defeitos que possam acometer a qualidade dos equipamentos, das imagens radiográficas e dos procedimentos relacionados ao exame radiográfico. Dessa forma, a chance de o diagnóstico ser inoclusivo ou equivocado é menor, tornando-o mais preciso. Logo, será desnecessária a repetição dos exames, expondo menos radiação ionizante ao paciente e utilizando menor tempo clínico (Brasil, 1998).

Durante o procedimento radiológico, o profissional é responsável pela proteção do paciente, utilizando técnica e equipamentos adequados. Além disso, deve assegurar aos pacientes a mínima exposição possível, levando em consideração também a melhor qualidade de imagem para se ter uma análise mais próxima do real estado do indivíduo (Brasil, 1998).

Os fatores que determinam uma qualidade adequada da radiografia são as características de densidade, contraste, nitidez e enquadramento do campo de interesse. Dessa forma, é notório que o processamento e o armazenamento do filme, os parâmetros de exposição e o posicionamento do filme e do paciente devem ser realizados de forma adequada para se obter imagens satisfatórias capazes de auxiliar na definição do diagnóstico e, consequentemente, na elaboração do plano de tratamento (Queiroga et al., 2010).

Durante a tomada radiográfica, o paciente recebe uma radiação, que independentemente da quantidade, pode causar efeitos deletérios ao organismo. Se esta exposição for pequena não será suficiente para provocar alteração clínica ou genética, porém será capaz de ocasionar uma 
reação celular com desorganização e quebra de moléculas. Os efeitos para pequenas doses de radiação não são conhecidos biologicamente com precisão, tanto para o desenvolvimento de uma lesão a nível somático como para uma mutação a nível genético. Porém, sabe-se que a nível somático há destruição dos tecidos nos quais a radiossensibilidade é maior, como em células de tecidos vasculares e as pertencentes aos órgãos sexual e oftálmico. Já a nível genético, ocorrem mutações que quebram os cromossomos contendo os genes, havendo reorganização aleatória e alterando o padrão hereditário (Mendonça et al., 2013; White \& Pharoah, 2007).

A técnica radiográfica periapical deve ser realizada de forma que o raio $\mathrm{X}$ incida perpendicularmente à bissetriz do ângulo formado entre o dente e $\mathrm{o}$ receptor de imagem, com o objetivo de registrar a região do periápice, periodonto e elemento dentário. Pode-se utilizar, também, a técnica do paralelismo, cujo o filme e o cilindro fiquem paralelos entre si. Logo, essas técnicas são indicadas para analisar os condutos radiculares, número e forma das raízes, lesões periapicais, lesões cariosas, crista óssea alveolar e região de furca (Tavano \& Alvares, 2011; Whaites, 2003).

Na técnica radiográfica oclusal o filme radiográfico deve ficar posicionado dentro da boca, de modo paralelo ao plano oclusal, coincidindo o meio do filme com a linha sagital mediana, visando capturar a mandíbula inteira ou a maxila inteira. Portanto, essa técnica é indicada para analisar dentes supranumerários, fraturas, raízes residuais, dentes inclusos, lesões, sialolitos, ortodontia e fendas palatinas (Tavano \& Alvares, 2011).

A radiografia interproximal também é chamada de bite wing (asa de mordida), pois o paciente necessita morder uma aleta que está presa ao filme para, assim, estabilizar o filme dentro da boca, e realizar a tomada radiográfica. Esta radiografia é realizada na técnica de paralelismo, de modo a investigar a região da coroa, colo dental e crista alveolar. A película é posicionada de modo a registrar, simultaneamente, toda a região de coroa da arca superior e inferior, possibilitando uma análise melhor da região interproximal. Consequentemente, essa técnica é indicada para verificar cáries interproximais em estágio inicial, reincidência de cárie, relação de cárie dental/câmara pulpar, adaptação de restaurações, cálculo gengival e relações entre germes decíduos e permanentes (Tavano \& Alvares, 2011).

As falhas na realização das técnicas durante a tomada radiográfica ou durante o processamento do filme radiográfico geram imagens insatisfatórias, cuja sua interpretação será inadequada, sendo necessária a repetição do exame, causando consequente aumento na exposição dos pacientes à radiação. Logo, gera um tempo profissional improdutível, desperdício de filmes radiográficos e soluções reveladoras e fixadoras, elevando os custos para instituições de ensino, serviços públicos e clínicas particulares (Mendonça et al., 2013; Carvalho et al., 2009, Dias et al., 2009; Kreich et al., 2002).

Alguns tipos de erros são clássicos para operadores que estão na graduação, pois são inexperientes e, dessa forma, possuem maior dificuldade de evitá-los. De acordo com estudos, a frequência de erros radiográficos cometidos por acadêmicos de odontologia é maior que $80 \%$. Dentre os erros cometidos nesses estudos, o posicionamento incorreto do filme, ranhuras, erros de processamento e angulação horizontal e/ou vertical foram os que mais se destacaram. Embora os erros de técnica e execução preponderem-se aos erros de processamento, não existe um acordo na literatura a respeito de qual erro é o mais frequente (Fernandes et al., 2010; Queiroga et al., 2010; Kreich et al., 2002; Matheus et al., 2000).

Os estudantes que estão prestes a se formarem possuem uma experiência maior do que os estudantes que acabaram de ingressar na graduação, e esta experiência pode interferir na realização correta da tomada radiográfica, já que os acadêmicos do último ano podem estar preocupados com outros procedimentos. Esse fato é alarmante, pois esses alunos podem levar esses vícios para a vida profissional (Silva et al., 2016).

A avaliação dos erros radiográficos mais decorrentes e a análise de suas causas permite identificar as falhas no processo de ensino, mostrando onde os docentes devem aprimorar e reforçar o processo de aprendizagem (Lima et al., 2010; Queiroga et al., 2010).

Para que se obtenha uma boa imagem radiográfica é imprescindível que todas as etapas de realização da técnica radiográfica sejam cumpridas rigorosamente, desde a posição do filme radiográfico, a posição da cabeça do paciente, incidência do feixe de raios $\mathrm{X}$, tempo de exposição e, por fim, as fases 
do processamento radiográfico (Eid \& Magalhães Filho, 2017; Carvalho et al., 2009).

$\mathrm{O}$ erro no posicionamento do paciente, do filme ou do aparelho de raios X gera imagens com sobreposição das superfícies proximais, imagens pouco nítidas e distorções, o que acarreta dimensões incorretas, tornando alongadas ou encurtadas. Esse tipo de erro pode ser prevenido utilizando aparelhos de raio X calibrados, posicionador de filmes radiográficos e posicionando a cabeça do paciente de forma correta, sendo que para radiografar na região da maxila, a cabeça do paciente deve ficar com o plano de camper paralelo ao solo. Já na região de mandíbula, deve-se posicionar a cabeça do paciente de forma que o plano tragus-comissura labial fique paralelo ao solo (Eid \& Magalhães Filho, 2017; Tavano \& Alvares, 2011).

As radiografias claras ocorrem por conta do tempo de exposição, escolha incorreta do tipo de filme, aumento da distância foco/filme com ausência de compensação de tempo de exposição, processamento incorreto e soluções deterioradas ou vencidas. Esse tipo de falha pode ser evitado realizando o processamento radiográfico de forma correta, usando soluções novas, trocando-as de acordo com as recomendações do fabricante e usando as tabelas de processamento temperatura/tempo ou método visual, pois se o tempo de revelação for curto, a imagem ficará clara (Eid \& Magalhães Filho, 2017; Tavano \& Alvares, 2011).

O erro de radiografias escuras ocorre devido ao tempo de exposição, escolha incorreta do tipo de filme, aumento da distância foco/filme com ausência de compensação de tempo de exposição, processamento incorreto e soluções deterioradas ou vencidas. A imagem possui menor nitidez e pouca definição nos detalhes, possuindo contraste inadequado dificultando a visualização do limite entre o esmalte e a dentina, o que complica a elucidação do diagnóstico. Essa falha pode ser prevenida utilizando local apropriado para o processamento radiográfico, sendo vedado à luz e usando as tabelas de processamento temperatura/tempo ou método visual, pois se o tempo de revelação for longo demais, a imagem ficará escura (Eid \& Magalhães Filho, 2017; Tavano \& Alvares, 2011).

As radiografias manchadas podem se apresentar com manchas amareladas, com manchas escuras por conta do revelador e manchas claras por conta do fixador. Esse tipo de erro ocorre pela laceração da emulsão e por falta ou inadequada lavagem, podendo ser prevenido usando tabelas de temperatura/tempo, ou método visual, mantendo as soluções limpas e fazendo a troca de acordo com as informações do fabricante e principalmente realizar uma lavagem adequada entre as soluções e depois do fixador (Eid \& Magalhães Filho, 2017; Tavano \& Alvares, 2011).

Importante ressaltar que tanto na técnica temperatura/tempo como na visual, o local deve ser apropriado para que não entre nenhuma luz e vele o filme radiográfico. Além disso, deve-se utilizar um protocolo de descarte e tratamento dos resíduos e efluentes produzidos pelo processamento do filme radiográfico (Eid \& Magalhães Filho, 2017; Carvalho et al., 2009; Kreich et al., 2002).

$\mathrm{O}$ estudo em questão tem o objetivo de quantificar e analisar os erros mais frequentes nas radiografias periapicais e interproximais realizadas por acadêmicos do $2^{\circ}$ ano do curso de Odontologia do Centro Universitário da Fundação Educacional de Barretos (UNIFEB), na disciplina de Radiologia, durante o período de um ano, visando melhorar o domínio da técnica correta pelos acadêmicos e, consequentemente, a qualidade das imagens radiográficas, para que sejam usadas na definição do diagnóstico e como documento legal.

\section{Material e Métodos}

Como primeiro procedimento do estudo, o projeto de pesquisa foi submetido para avaliação do Comitê de Ética em Pesquisa (CEP) da Faculdade Ceres de Medicina, de São José do Rio Preto - FACERES para análise, sob o CAAE 90736618.0.0000.8083, sendo considerado aprovado e dispensado o uso do Termo de Consentimento Livre Esclarecido (TCLE), pois não envolveu dados de seres humanos direta ou indiretamente. Foram quantificadas e analisadas radiografias intraorais (periapicais, oclusais e interproximais) realizadas por acadêmicos durante a disciplina de Radiologia do curso de Odontologia da UNIFEB, no período de 01 de agosto de 2018 a 31 de julho de 2019.

O aparelho utilizado para realizar a exposição radiográfica na técnica da bissetriz sem posicionador foi o GNATUS intrabucal fixo na parede (Gnatus - Equipamentos Médicos-Odontológicos LTDA, São Paulo, Brasil), utilizando 50KV, 7,5mA e usando 0,5 e 0,63 segundos de exposição. Os filmes radiográficos foram processados manualmente em câmara escura de labirinto, empregando o método visual de processamento. As radiografias que 
foram avaliadas nesta pesquisa são aquelas que os alunos entregaram aos docentes como satisfatórias e insatisfatórias. Foi utilizado negatoscópio móvel (BIOTRON telerradiográfico ultraslim branco - Equipamentos Médicos LTDA, Santa Rita do Sapucaí, Minas Gerais, Brasil), lupa (4X) e sala escura para auxiliar na análise das imagens radiográficas.

Para avaliação das radiografias insatisfatórias foram adotados os seguintes critérios:

\section{Erros de técnica radiográfica:}

A) Enquadramento incorreto do filme radiográfico: subdividido em posicionamento errado do filme e cortes de um ou mais dentes;

B) Enquadramento de cilindro do aparelho de raio $X$ : área de incidência dos feixes de raio $X$;

C) Angulagem do cilindro do aparelho de raio X: subdividida em angulagem vertical (alongamento e encurtamento) e horizontal (sobreposição);

D) Dupla Exposição: duas ou mais exposições em um único filme radiográfico;

E) Definição de imagem: radiografias sem contorno e nitidez devido ao movimento do filme, do cilindro e/ou do paciente, durante a tomada radiográfica. Imagens com limite indefinido entre esmalte e dentina;

F) Exposição na face da lâmina de chumbo;

G) Picote: radiografias que não estão com o picote posicionado para a face oclusal dos dentes.

\section{Erro de processamento das radiografias:}

Radiografias mal reveladas ou fixadas, com manchas amareladas por mal lavagem. Radiografias riscadas, com impressões digitais ou coladas.

A análise de todas as radiografias foi feita por dois examinadores treinados pelos docentes responsáveis pelo conteúdo de Radiologia Odontológica da UNIFEB, com o intuito de garantir a confiabilidade e a padronização na coleta de dados e resultados finais. Os dados foram apresentados por meio de tabelas comparando os tipos de erros e suas frequências, utilizando o método da estatística descritiva. Os critérios de avaliação das radiografias foram utilizados para a confecção de um protocolo de pesquisa para que este fosse utilizado para computar as informações obtidas durante as análises das radiografias.

Nas radiografias interproximais não há a subdivisão do grupo angulagem vertical e não há o grupo de posicionamento incorreto do picote. Isso porque se houver erro de angulagem vertical, haverá alongamento e encurtamento no mesmo filme radiográfico, já que o plano oclusal se localiza no meio do filme. O erro de posicionamento incorreto do picote foi retirado, pois em qualquer lado em que for posicionado, ele estará voltado para a oclusal. Logo, na radiografia interproximal não existe erro de posicionamento incorreto do picote.

\section{Resultados e Discussão}

Foram avaliadas no total 2899 radiografias, sendo 816 radiografias satisfatórias e 2083 radiografias insatisfatórias, subdividindo-se em 1642 radiografias periapicais, 100 radiografias oclusais e 341 radiografias interproximais. As radiografias periapicais foram realizadas na técnica da bissetriz e sem posicionador, mas as radiografias oclusais foram realizadas na técnica do paralelismo. Já as radiografias interproximais foram realizadas na técnica do paralelismo, utilizando fita adesiva para confeccionar a asa de mordida (bite wing) ou o posicionador.

$\mathrm{Na}$ análise das radiografias periapicais houve $22,42 \%$ de erro de enquadramento do filme, sendo $12,23 \%$ de erro de posicionamento do filme e $10,18 \%$ de erro de cortes de um ou mais dentes. Houve 4,47\% de erro de área de incidência, 20,63\% de erro de angulagem vertical, sendo $13,40 \%$ de alongamento e $7,22 \%$ de encurtamento, $7,65 \%$ de erro de angulagem horizontal (sobreposição de imagem), $0,17 \%$ de erro de dupla exposição, $4,45 \%$ de erro de definição de imagem, $2,19 \%$ de erro de picote posicionado incorretamente, $0,49 \%$ de erro de exposição da face da lâmina de chumbo, $8,86 \%$ de erro de radiografia mal revelada, $5,56 \%$ de erro de radiografia mal fixada, $9,93 \%$ de erro de radiografia mal lavada e $13,15 \%$ de erro de radiografias riscadas, com impressão digital ou coladas.

$\mathrm{Na}$ análise das radiografias oclusais houve $23,66 \%$ de erro de enquadramento do filme, sendo $12,05 \%$ de erro de posicionamento incorreto do filme, $11,60 \%$ de erro de cortes de um ou mais 
dentes, $13,61 \%$ de erro de área de incidência, $15,17 \%$ de erro de angulagem vertical, sendo $6,02 \%$ de erro de alongamento, $9,15 \%$ de erro de encurtamento, $4,91 \%$ de erro de angulagem horizontal, $0,66 \%$ de erro de dupla exposição, $4,68 \%$ de erro de definição de imagem, $0,44 \%$ de erro de picote posicionado incorretamente, $0,66 \%$ de erro de exposição da face da lamina de chumbo, $4,46 \%$ de erro de radiografia mal revelada, 5,35\% de erro de radiografia mal fixada, $13,83 \%$ de erro de radiografia mal lavada e $12,50 \%$ de erro de radiografias riscadas, com impressão digital ou coladas.

$\mathrm{Na}$ análise das radiografias interproximais houve $28,41 \%$ de erro de enquadramento do filme, sendo $17,43 \%$ de erro de posicionamento incorreto do filme, $10,97 \%$ de erro de cortes de um ou mais dentes, $8,18 \%$ de erro de área de incidência, $3,44 \%$ de erro de angulagem vertical, $17,97 \%$ de erro de angulagem horizontal, $0,21 \%$ de erro de dupla exposição, 5,92\% de erro de definição de imagem, $0,00 \%$ de erro de exposição da face da lamina de chumbo, $6,24 \%$ de erro de radiografia mal revelada, $6,45 \%$ de erro de radiografia mal fixada, $9,68 \%$ de erro de radiografia mal lavada e $13,45 \%$ de erro de radiografias riscadas, com impressão digital ou coladas.

De acordo com a literatura e com os resultados deste trabalho, uma imagem radiográfica considerada de boa qualidade deve possuir os seguintes critérios: máxima nitidez, apresentar definição das estruturas anatômicas, posicionamento correto do filme e do cilindro de raio $\mathrm{X}$, para evitar distorções, densidade correta e contraste adequado (Mendonça et al., 2013; Gasparini et al., 2005; Kreich et al., 2002).

Além disso, as radiografias com presença de erros na técnica radiográfica e/ou no processamento geram imagens inadequadas, o que faz perder o valor legal do documento radiográfico e resultam em uma interpretação incorreta. A grande maioria das radiografias que continham alguma falha impossibilitavam ou distorciam a interpretação do diagnóstico (Mendonça et al., 2013; Matheus et al., 2000).

É importante ressaltar que a lavagem entre soluções e, principalmente, a final é de extrema importância para que a imagem radiográfica não possua a presença de manchas, possibilitando uma visualização correta da imagem, auxiliando no diagnóstico e sendo digna de um documento legal. Durante a análise das radiografias, muitas estavam corretas na técnica de obtenção da imagem, porém continham falhas no processamento, o que causa manchas e dificulta a visualização fidedigna (Silva et al., 2016).

Pode-se observar que o erro de maior frequência nas radiografias periapicais (Tabela 1), em relação aos erros de técnica radiográfica, foi o de enquadramento do filme $(22,42 \%)$, sendo o de posicionamento incorreto do filme o que mais ocorreu (12,23\%). O erro de segunda maior frequência, ainda nos erros de técnica, foi o de angulagem vertical (20,63\%), sendo que, deste grupo, o erro de alongamento foi o mais ocorrido (13,40\%). Esta porcentagem de angulagem vertical foi próxima dos resultados de Mendonça et al. (2013) Matheus et al. (2000), Kreich et al. (2002), Pontual et al. (2005), Felippe et al. (2009), Carvalho et al. (2009), Dias et al. (2009) e Guimarães et al. (2011). Além disso, o erro de terceira maior frequência foi o de angulagem horizontal $(7,65 \%)$.

Nos erros de processamento de imagem, nas radiografias periapicais (Tabela 1), o que possui maior frequência é o erro de radiografias riscadas, com impressão digital ou coladas (13,15\%), seguido do erro de radiografias mal lavadas $(9,93 \%)$ e radiografias mal reveladas $(8,86 \%)$. No estudo de Mendonça et al. (2013), as falhas que causam manchas também foram as que mais ocorreram nos erros de processamento.

$\mathrm{Na}$ Figura 1 pode-se analisar os subgrupos e os grupos que não possuem subgrupos, ou seja, uma visão geral, e desta forma nota-se que o erro mais frequente é o de alongamento $(13,40 \%)$, seguido do erro de radiografias riscadas, com impressão digital ou coladas $(13,15 \%)$ e do erro de posicionamento incorreto do filme (12,23\%). Tal resultado é corroborado pelo estudo de Mendonça et al. (2013), mostrando, também, que a angulagem vertical foi o erro mais cometido.

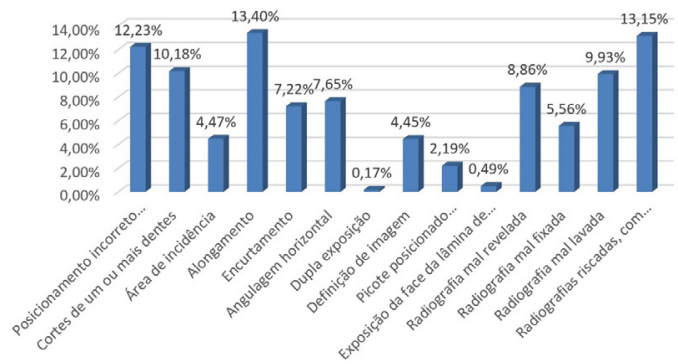

Figura 1. (Erros de Radiografia Periapical). 
Tabela 1. (Análise da quantidade dos erros de radiografias periapicais, oclusais e interproximais e suas respectivas porcentagens.)

\begin{tabular}{|c|c|c|c|c|c|c|}
\hline \multirow{2}{*}{$\begin{array}{l}\text { ERROS DE TÉCNICA } \\
\text { RADIOGRÁFICA }\end{array}$} & \multicolumn{2}{|c|}{$\begin{array}{l}\text { RADIOGRAFIA } \\
\text { PERIAPICAL }\end{array}$} & \multicolumn{2}{|c|}{$\begin{array}{c}\text { RADIOGRAFIA } \\
\text { INTERPROXIMAL } \\
\end{array}$} & \multicolumn{2}{|c|}{$\begin{array}{l}\text { RADIOGRAFIA } \\
\text { OCLUSAL }\end{array}$} \\
\hline & $\begin{array}{l}\mathrm{N}^{\circ} \text { de } \\
\text { erros }\end{array}$ & \% Erros & $\begin{array}{l}\mathrm{N}^{0} \mathrm{de} \\
\text { erros }\end{array}$ & \% Erros & $\begin{array}{l}\mathrm{N}^{0} \mathrm{de} \\
\text { erros }\end{array}$ & \% Erros \\
\hline $\begin{array}{l}\text { Enquadramento incorreto do filme } \\
\text { radiográfico }\end{array}$ & 1052 & 22,42 & 264 & 28,41 & 106 & 23,66 \\
\hline Posicionamento incorreto do filme & 574 & 12,23 & 162 & 17,43 & 54 & 12,05 \\
\hline Cortes de um ou mais dentes & 478 & 10,18 & 102 & 10,97 & 52 & 11,60 \\
\hline Área de incidência & 210 & 4,47 & 76 & 8,18 & 61 & 13,61 \\
\hline Angulagem vertical & 968 & 20,63 & 32 & 3,44 & 68 & 15,17 \\
\hline Alongamento & 629 & 13,40 & - & - & 27 & 6,02 \\
\hline Encurtamento & 339 & 7,22 & - & - & 41 & 9,15 \\
\hline Angulagem horizontal & 359 & 7,65 & 167 & 17,97 & 22 & 4,91 \\
\hline Dupla exposição & 8 & 0,17 & 2 & 0,21 & 3 & 0,66 \\
\hline Definição de imagem & 209 & 4,45 & 55 & 5,92 & 21 & 4,68 \\
\hline $\begin{array}{l}\text { Picote posicionado incorretamente } \\
\text { (não oclusal) }\end{array}$ & 103 & 2,19 & - & - & 2 & 0,44 \\
\hline $\begin{array}{l}\text { Exposição da face da lâmina de } \\
\text { chumbo }\end{array}$ & 23 & 0,49 & 0 & 0,00 & 3 & 0,66 \\
\hline \multicolumn{7}{|l|}{$\begin{array}{l}\text { ERROS DE } \\
\text { PROCESSAMENTO DE } \\
\text { IMAGEM }\end{array}$} \\
\hline Radiografia mal revelada & 416 & 8,86 & 58 & 6,24 & 20 & 4,46 \\
\hline Radiografia mal fixada & 261 & 5,56 & 60 & 6,45 & 24 & 5,35 \\
\hline Radiografia mal lavada & 466 & 9,93 & 90 & 9,68 & 62 & 13,83 \\
\hline $\begin{array}{l}\text { Radiografias riscadas, com } \\
\text { impressão digital ou coladas }\end{array}$ & 617 & 13,15 & 125 & 13,45 & 56 & $12,50 \%$ \\
\hline $\begin{array}{l}\text { TOTAL DE ERROS } \\
\text { RADIOGRÁFICOS }\end{array}$ & 4692 & 100,00 & 929 & 100,00 & 448 & 100,00 \\
\hline $\begin{array}{l}\text { TOTAL DE RADIOGRAFIAS } \\
\text { ANALISADAS }\end{array}$ & \multicolumn{2}{|c|}{1642} & \multicolumn{2}{|c|}{341} & \multicolumn{2}{|c|}{100} \\
\hline
\end{tabular}

De acordo com a Tabela 1, pode-se observar tanto neste estudo como nos de Mendonça et al. (2013) e Kreich et al. (2002) que há muito mais quantidade de erros de técnica radiográfica do que de processamento de imagem. Isso acontece porque, a técnica radiográfica possui mais etapas do que o processamento de imagem. Logo, os alunos possuem maior chance de errar na técnica do que no processamento.

Nas radiografias oclusais o erro de maior frequência (Tabela 1), em relação aos erros de técnica radiográfica, também foi o de enquadramento do filme $(23,66 \%)$, sendo o erro de posicionamento incorreto do filme $(12,05 \%)$ o que mais ocorre neste grupo, seguido de angulagem vertical $(15,17 \%)$, sendo o encurtamento $(9,15 \%)$ o que mais ocorre neste grupo. Por fim, o erro de terceira maior frequência é o erro de área de incidência
$(13,61 \%)$. Estes resultados estão de acordo com a literatura (Mendonça et al., 2013).

Em relação ao processamento de imagem das radiografias oclusais (Tabela 1), o erro de maior frequência foi o erro de radiografias mal lavadas $(13,83 \%)$, seguido do erro de radiografias riscadas, com impressão digital ou coladas $(12,50 \%)$ e do erro de radiografias mal fixadas $(5,35 \%)$. Estes dados estão embasados na literatura, pois o estudo de Fernandes et al. (2010) mostrou que os erros que causam manchamento são os mais frequentes no processamento de imagem.

Na figura 2 pode-se analisar os subgrupos e os grupos que não possuem subgrupos, ou seja, uma visão geral. Desta forma nota-se que o erro mais frequente é o de radiografia mal lavada $(13,83 \%)$, seguido do erro de área de incidência $(13,61 \%) \mathrm{e}$ do erro de radiografias riscadas, com impressão 
digital ou coladas $(12,50 \%)$. Fernandes et al. (2010) e Mendonça et al. (2013) corroboram este resultado, pois em seus trabalhos o erro de manchamento também é o mais frequente.

Além disso, foi notada uma porcentagem de $31,89 \%$ de radiografias satisfatórias, estando de acordo com o trabalho de Silva et al. (2016), já que relataram que os alunos do $2^{\circ}$ ano realizaram $71,86 \%$ de radiografias insatisfatórias e, consequentemente, realizaram $28,14 \%$ de radiografias satisfatórias.

Analisando a quantidade de erros das radiografias periapicais com as radiografias oclusais, pode-se notar que existe uma quantidade de erros bem inferior nas radiografias oclusais. O motivo que explica este fato é que a quantidade de radiografias periapicais para a realização de um status radiográfico é bem maior que a quantidade de radiografias oclusais e os alunos iniciam o bimestre realizando apenas tomadas radiográficas periapicais e ao longo do primeiro bimestre começam a realizar as tomadas radiográficas oclusais, possuindo um maior volume de prática. No estudo de Mendonça et al. (2013) é observado o mesmo fato, um número expressivamente menor de radiografias oclusais comparado ao de periapicais.

Nas radiografias interproximais, o erro de maior frequência (Tabela 1) em relação aos erros de técnica radiográfica também foi o de enquadramento do filme $(28,41 \%)$, sendo o erro de posicionamento incorreto do filme o mais ocorrido (17,43\%), seguido do erro de angulagem horizontal $(17,97 \%)$ e do erro de área de incidência $(8,18 \%)$. Mendonça et al. (2013) relatam que o erro de enquadramento é um dos mais frequentes em seu trabalho.

Em relação ao processamento de imagem das radiografias interproximais (Tabela 1), o erro de maior frequência foi o erro de radiografias riscadas, com impressão digital ou coladas (13,45\%), seguido do erro de radiografias mal lavadas $(9,68 \%)$ e do erro de radiografias mal fixadas $(6,45 \%)$. Desta forma, é notório que os erros de manchamento costumam estar entre os mais frequentes no quesito de processamento de imagem (Mendonça et al., 2013; Fernandes et al., 2010)

$\mathrm{Na}$ Figura 3 pode-se analisar os subgrupos e os grupos que não possuem subgrupos, ou seja, uma visão geral. Desta forma, nota-se que o erro mais frequente é o de angulagem horizontal (17,97\%), seguido do erro de posicionamento incorreto do filme $(17,43 \%)$ e do erro de radiografias riscadas,

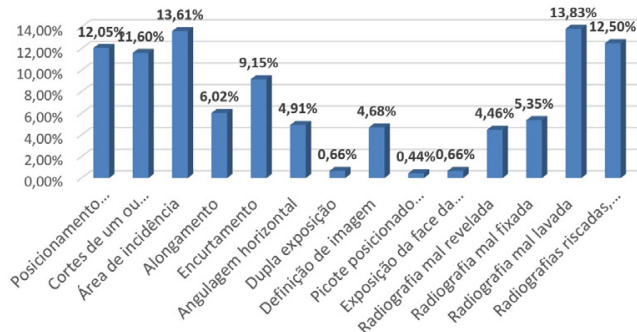

Figura 2. (Erros de Radiografia Oclusal).

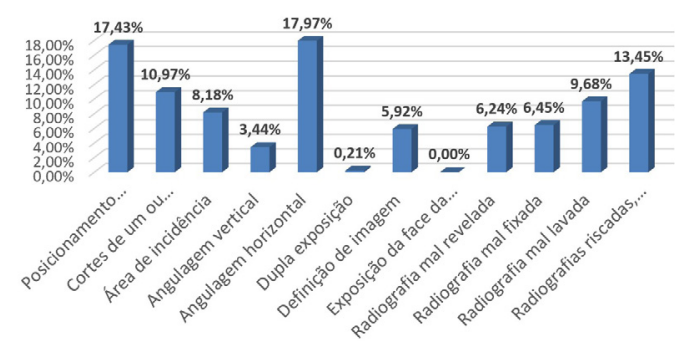

Figura 3. (Erros de Radiografia Interproximal).

com impressão digital ou coladas $(13,45 \%)$. Guimarães et al. (2009) mostram em seu artigo que nas radiografias interproximais, a angulação horizontal incorreta foi o erro mais prevalente.

É importante ressaltar que à medida que os alunos vão adquirindo prática, consequentemente vão cometendo menos quantidade de erros, assim como comprovado nos estudos de Mendonça et al. (2013), Queiroga et al. (2010) e Carvalho et al. (2009), pois foi observada uma redução do número de erros radiográficos ao longo da prática acadêmica.

\section{Conclusão}

Nas radiografias periapicais o erro que mais ocorreu, no critério de técnica, foi o de alongamento. Já no critério processamento de imagem, foi o de radiografias riscadas, com impressão digital ou coladas.

Nas radiografias oclusais a falha mais cometida, para o critério de técnica, foi a área de incidência. No critério de processamento de imagem, foram radiografias mal lavadas.

Nas interproximais, no critério de técnica, o erro mais frequente foi o de angulagem horizontal. No critério processamento de imagem, o principal equívoco foi o de radiografias riscadas, com impressão digital ou coladas. 
Logo, durante o processo de aprendizagem dos alunos, deve-se dar um enfoque maior nessas respectivas fases de realização da técnica e do processamento de imagem. Desta forma, os alunos vão diminuir a quantidade de falhas cometidas, obtendo imagens adequadas para o diagnóstico, possuindo valor legal e prevenindo a exposição de raio $\mathrm{X}$ em excesso ao paciente.

\section{Agradecimento}

Agradecemos ao UNIFEB pela estrutura e ao $\mathrm{CNPq}$ pelo fomento a esta pesquisa.

\section{Referências}

Brandt, C., Fenyo Pereira, M., Costa, C., \& Varoli, O. J. (1997). A influência do ensino da técnica radiográfica periapical do paralelismo preliminarmente ao da técnica radiográfica periapical da bissetriz. Revista de Odontologia da Universidade de São Paulo, 11(2), 131-137.

Brasil. Ministério da Saúde. Secretaria de Vigilância Sanitária. (1998). Diretrizes de proteção radiológica em radiodiagnóstico médico e odontológico: regulamento técnico do Ministério da Saúde. Brasília: Ministério da Saúde.

Carvalho, P. L., Neves, A. C. C., Medeiros, J. M. F., Zõllner, N. A. R., \& Almeida, L. D. (2009). Erros técnicos nas radiografias intrabucais realizadas por alunos de graduação. Revista Gaucha de Odontologia, 57(2), 151-155.

Dias, I. M., Furiati, P. F., Santos, E. E., Barros, C. C., \& Devito, K. L. (2009). Análise de erros radiográficos cometidos por acadêmicos da Faculdade de Odontologia de Juiz de Fora. Arquivos Em Odontologia, 45(1), 51-56.

Eid, N. L. M., \& Magalhães Filho, G. (2017). Erros na Aquisição de Radiografias Periapicais Realizadas Por Acadêmicos Do Centro Universitário UNIRG. RvAcBO, 26(1):14-20. Recuperado em 13 de fevereiro de 2019, de http://www.rvacbo. com.br/ojs/index.php/ojs/article/view/319

Felippe, M. C. S., Nassri, M. R. G., Burgos, P. G., Freitas, S. F. T., \& Lage-Marques, J. L. (2009). Qualidade de radiografias periapicais realizadas por graduandos durante o tratamento endodôntico. RSBO, 6(1), 63-69.
Fernandes, A. M., Aguiar, A. P. S., Da Cruz, L. P., Aivazoglou, M. U., Gomes, A. P. M., \& Da Silva, E. G. (2010). Avaliação dos erros radiográficos cometidos por alunos de graduação durante o tratamento endodôntico. Revista de Odontologia da Universidade Cidade de São Paulo, 22(3):216-222.

Gasparini, A. L., Lemke, F., Carvalho, A. S., Cunha, F. L., Junqueira, J. L. C., \& Tavano, O. (2005). Verificação das condições do processamento radiográfico em consultórios odontológicos. $R G O$, 53(3), 217-219.

Guimarães, C. S., Pontual, A. A., Khoury, H. J., Rodrigues, C. D., Estrela, C., \& Silveira, M. M. F. (2011). Qualidade de imagens radiográficas processadas em consultórios odontológicos e em laboratório. ROBRAC, 20(52)

Guimarães, S., Costa, C., Rosa, R., Medici Filho, E., Castilho, J., \& Faig-Leite, H. (2009). Avaliação dos erros radiográficos mais comuns em uma clínica de radiodiagnóstico. Revista ABRO. 10(1):38-44.

Kreich, E. M., Queiroz, M. G. S., \& Sloniak, M. C. (2002). Controla de qualidade em radiografias periapicais obtidas no curso de odontologia da UEPG. Publicatio UEPG - Ciência Biológicas e da Saúde, 8(1), 33-45. Recuperado em 24 de abril de 2018, de http://177.101.17.124/index. php/biologica/article/view/275/280

Lima, L. R., Lima Júnior, G. T. D. A., Machado Filho, J. A., \& Freitas, S. A. P. (2010). Avaliação da qualidade e do arquivamento de radiografias periapicais na clínica de endodontia da Faculdade NOVAFAPI. Odontologia Clínico-Cientifica, 9(4), 355-358.

Matheus, R. A., Montebelo Filho, A., Tanaka, E. E., \& Barros, R. M. (2000). Avaliaçäo no desempenho de acadêmicos durante tomadas radiográficas periapicais, pela técnica da bissetriz, realizada na Faculdade de Odontologia da Universidade Norte do Paraná (Unopar). RFO UPF, 5(2), 25-29.

Mendonça, D. M., Amorim, M. E. B., Medina, P. O., Alves Filho, A. O., Brito, T. C. C. A., \& Conde, N. C. O. (2013). Avaliação de Erros em Exames Radiográficos Intrabucais Realizada por Acadêmicos de Odontologia/UFAM. Revista de Odontologia da Universidade Cidade de São Paulo, 26(2): 119-26. Recuperado em 13 de fevereiro de 
2019, de http://publicacoes.unicid.edu.br/index. php/revistadaodontologia/article/view/298

Pontual, M. L. A., Pinho Veloso, H. H., Pontual, A. A., \& Fonseca Silveira, M. M. (2005). Errores en radiografias intrabucales realizadas en la Facultad de Odontología de Pernambuco-Brasil. Acta Odontologica Venezolana, 43(1), 19-24.

Queiroga, M. A. S., Moreno, N. P. P., Figueiredo, C. B. O., Abreu, M. H. N. G., \& Brasileiro, C. B. (2010). Avaliação dos erros radiográficos cometidos por graduandos de odontologia em técnicas radiográficas intrabucais. Arquivos Em Odontologia, 46(3), 61-65.

Silva, M. F. S., Oliveira, L. C., Daroz, B. G., Peyneau, P. D., Pareira, T. C. R., \& Vaz, S. L. A. (2016). Erros cometidos por estudantes de Odontologia de uma universidade pública brasileira na realização de radiografias periapicais. Revista da ABENO, 16(1), 99-109. Recuperado em 24 de abril de 2018, de https://revabeno.emnuvens.com. br/revabeno/article/view/245/205

Tavano, O., \& Alvares, L. C. (2011). Curso de Radiologia em Odontologia (5. ed.). São Paulo: Santos.

Teunen, D. (1998). The European Directive on health protection of individuals against the dangers of ionising radiation in relation to medical exposures (97/43/EURATOM). Journal of Radiological Protection, 18(2), 133-137.

Whaites, E. (2003). Princípios de radiologia odontológica (3. ed.). Porto Alegre: Artmed.

White, S., \& Pharoah, M. (2007). Radiologia oral: fundamentos e interpretação (5. ed.). Rio de Janeiro: Elsevier. 